NBER WORKING PAPER SERIES

\title{
GIRL POWER: CASH TRANSFERS AND ADOLESCENT WELFARE. EVIDENCE FROM A CLUSTER-RANDOMIZED EXPERIMENT IN MALAWI
}

\author{
Sarah J. Baird \\ Ephraim Chirwa \\ Jacobus de Hoop \\ Berk Özler \\ Working Paper 19479 \\ http://www.nber.org/papers/w19479 \\ NATIONAL BUREAU OF ECONOMIC RESEARCH \\ 1050 Massachusetts Avenue \\ Cambridge, MA 02138 \\ September 2013
}

Raka Banerjee, Diana Boss, Josefine Durazo, Fernando Galeana, Nicola Hedge, Cara Janusz, Amanda Moderson-Kox, Lucie Tafara Moore, James Mwera and Erin Shedd provided excellent research assistance on the SIHR project. We are grateful to participants at the National Bureau of Economic Research (NBER) Africa Project Research Conference for valuable comments. We gratefully acknowledge funding from the Global Development Network, the Bill and Melinda Gates Foundation, NBER Africa Project, World Bank Research Support Budget Grant, 3ie Open Window (Round 2) as well as several trust funds at the World Bank: Knowledge for Change Trust Fund (TF090932), World Development Report 2007 Small Grants Fund (TF055926), Spanish Impact Evaluation Fund (TF092384), and Gender Action Plan Trust Fund (TF092029). Please send correspondence to: sarah.baird@otago.ac.nz. The views expressed herein are those of the authors and do not necessarily reflect the views of the National Bureau of Economic Research.

NBER working papers are circulated for discussion and comment purposes. They have not been peerreviewed or been subject to the review by the NBER Board of Directors that accompanies official NBER publications.

(C) 2013 by Sarah J. Baird, Ephraim Chirwa, Jacobus de Hoop, and Berk Özler. All rights reserved. Short sections of text, not to exceed two paragraphs, may be quoted without explicit permission provided that full credit, including (C) notice, is given to the source. 
Girl Power: Cash Transfers and Adolescent Welfare. Evidence from a Cluster-Randomized Experiment in Malawi

Sarah J. Baird, Ephraim Chirwa, Jacobus de Hoop, and Berk Özler

NBER Working Paper No. 19479

September 2013

JEL No. C93,I10,I21,I38

\begin{abstract}
Interventions targeting adolescent girls are seen as a key component in the fight to break the cycle of poverty in developing countries. Policies that enable them to reach their full potential can have a strong impact not only on their own wellbeing, but also on that of future generations. This paper summarizes the short-term impacts of a cash transfer program on the empowerment of adolescent girls in Malawi during and immediately after the two-year intervention. We find that the program, which transferred cash directly to school-age girls as well as their parents, had effects on a broad range of important domains - including increased access to financial resources, improved schooling outcomes, decreased teen pregnancies and early marriages, better health - and generally enabled beneficiaries to improve their agency within their households. Underlying these overall impacts, the experiment revealed important differences in program effects between young women who were in school at the start of the intervention and those that were not, as well as between young women who received cash transfers conditionalon regular school attendance and those who received cash unconditionally. The results point to the potential role that cash transfer programs can play in improving the lives of adolescent girls in Sub-Saharan Africa, as well as the heterogeneity of effects under different program designs.
\end{abstract}

Sarah J. Baird

Department of Economics and

Department of Preventive and Social Medicine

University of Otago

Dunedin, New Zealand

and George Washington University

sarah.baird@otago.ac.nz

Ephraim Chirwa

Department of Economics

Chancellor College

University of Malawi

Zomba, Malawi

echirwa@yahoo.com
Jacobus de Hoop

International Labour Office for Italy \& San Marino

Rome, Italy

jdehoop@ucw-project.org

Berk Özler

Department of Economics

University of Otago

Dunedin, New Zealand

and The World Bank

berk.ozler@otago.ac.nz 


\section{INTRODUCTION}

Adolescent girls are a key demographic target group to successfully break the cycle of poverty in developing countries (Levine et al. 2008). In Malawi, the focus of this paper, the population of 15-19 year old girls is forecast to grow by $66.9 \%$ from 2005 to 2020 , making its projected growth-rate the third highest in the world (Warhurst, Molyneux, and Jackson 2010). ${ }^{2}$ Interventions that help adolescent girls reach their full potential not only bring immediate benefits to their own lives, but also longer-term benefits to their offspring and communities at large (Lloyd 2009; Duflo 2012). This message is the focus of organizations that favor social interventions targeted at young women, such as the Coalition for Adolescent Girls founded by the United Nations Foundation and the Nike Foundation. ${ }^{3}$

This paper examines whether a cash transfer program targeted at adolescent girls in Malawi helped empower its recipients in the short-run, i.e. during and immediately after the twoyear intervention. The Zomba Cash Transfer Program (ZCTP) was a randomized intervention that provided initially never-married females aged 13-22 with financial support in the form of monthly cash transfers for two academic years. The intervention had two treatment arms, one where cash was given conditional on regular school attendance, the Conditional Cash Transfer (CCT) arm, and one that transferred cash unconditionally, the Unconditional Cash Transfer (UCT) arm. The program was not only targeted to families of eligible young females as described above, but also, unlike in almost all CCT programs, part of the monthly transfer was given directly to the girl. Giving transfers to girls directly can make the transfers "stick" to them, potentially leading to larger impacts (see Muralidharan and Prakash 2013 for strong enrollment effects of a program that gave girls bicycles in India). Furthermore, as in BRAC's Empowerment and Livelihoods for Adolescents (ELA) program in Uganda, girls who had already dropped out of school were part of the target population under ZCTP, allowing for the identification of impacts

\footnotetext{
${ }^{2}$ As of 2005 , there were 849.6 million girls aged 10-24 in the world, comprising $13 \%$ of the global population. Between 2005 and 2020, the population of girls aged 10-24 years is forecast to grow by 5.1\% (Warhurst, Molyneux, and Jackson 2010).

${ }^{3}$ See, for example, "The Girl Effect", a YouTube sensation that advocates for "the powerful social change brought about when girls have the opportunity to participate." http://www.youtube.com/user/girleffect
} 
separately on this potentially vulnerable group. The target population and the experimental variation in treatment make the ZCTP an ideal intervention within which to evaluate the impact of cash transfers on the empowerment of adolescent girls. ${ }^{4}$

However, it is important to note that the notion of empowerment adopted here for this group of young and largely never-married females at the end of the two-year intervention is different than what we would consider if the target population were mostly married adult women. As is powerfully summarized in Duflo (2012), many academics and policymakers are interested in women's decision-making power within their households, their bargaining power within their marriages, and their voice and political power within their communities. As the study population here are initially never-married adolescent girls, the vast majority of whom still lived with their parents (or another guardian) at the end of the two-year program, outcomes pertaining to bargaining power within marriage, investments in own children, or involvement in local politics are too early to measure. Potential program impacts on these outcomes are the focus of future work using longer-term follow-up data. Here, we focus on the empowerment of adolescent girls and summarize program impacts for a wide and rich set of outcomes during and immediately following the completion of the cash transfer experiment.

Empowerment, as a concept, is hard to pin down. Kabeer (1999) defines empowerment as "the process by which those who have been denied the ability to make strategic life choices acquire such ... ability". Essentially, Kabeer (1999) argues that two elements, resources and agency, ${ }^{5}$ determine an individuals' ability to exercise choice. Resources can broadly be defined as access and future claims to physical and human resources that are instrumental in making important choices in life. Agency is "people's actual capacity to define their own life-choices and to pursue their own goals" (Kabeer 1999). Agency includes both internal cognitive processes such as reflection and analysis and the social processes of bargaining, negotiation, manipulation, norms, and conventions. Ultimately, improved ability to exercise choice (as a result of enhanced

\footnotetext{
${ }^{4}$ We discuss the details of these two different treatment arms in more detail in Section 2.

${ }^{5}$ Sen (1999) refers to this as capabilities.
} 
resources and agency) can affect day-to-day functioning of the individual and her family members (for instance in terms of health status, nutritional intake, and time use).

While the literature approaches empowerment from multiple angles, it can largely be interpreted within the framework of Kabeer (1999) as investigating the impact of enhanced resources or agency on subsequent functioning. In economics, the empirical literature largely focuses on policies or programs that increase a woman's bargaining power within marriage, both improving own outcomes as well as those of her children. For example, policies such as the old age pension in South Africa (Duflo 2003) and extended alimony rights in Brazil (Rangel 2006) had beneficial impacts on the health and education of the female children of beneficiaries. In addition, there is some evidence that female targeted interventions improve outcomes for women: a switch from a tax credit to a direct payment to the mother for child benefits was associated with an increase in the consumption of women's and children's clothing (Lundberg, Pollak, and Wales 1997); a savings product in the Philippines improved women's influence on household decisions (Karlan, Ashraf and Yin 2007); a micro-credit program in Bangladesh increased the female beneficiaries financial resources and mobility (Pitt, Khandker, and Cartwright 2006); a community level education program for women improved employment and empowerment outcomes (Kandpal, Baylis and Arends-Kuenning 2013); and Oportunidades, a Mexican CCT scheme, empowered women by encouraging them to negotiate better care from healthcare providers (Barber and Gertler 2010). ${ }^{6}$ More relevant for the target population of adolescent girls under examination here, Bandiera et al. (2012) find that an intervention that combined vocational training with information on health and risky behaviors led to increases in income-generating activities and decreases in sexual activity and pregnancies among females aged 14-20 in Uganda.

\footnotetext{
${ }^{6}$ While giving women more power is on many occasions both efficiency and equity enhancing, Duflo (2012) notes that women and men have different preferences and women's preferences are not always more benevolent than men's and their decisions are not always more favorable to well-being and development. For example, girls aged 0-5 benefited from old age pensions given to women but not to men, and there was no effect among boys for either recipient (Duflo 2003). Under the same program schooling for children aged 13-17 increased more when the eligible recipient was male (Edmonds 2006). Ashraf, Field, and Lee (2012) show that women who are empowered to take charge of birth control decisions through concealable contraceptives in Zambia report a lower subjective wellbeing.
} 
Within the theoretical economics literature, the discourse on female empowerment focuses on shifts in the balance of power within married couples in favor of the woman. A shift in the balance of power can take different forms, such as an increase in the woman's education, an increase in her earning capacity, or her improved access to birth control technologies. Such shifts can result in the reallocation of resources within the household towards the woman (Chiappori, Iyigun, and Weiss 2009; Chiappori and Oreffice 2008), both increasing her welfare and perhaps leading to a reduction in total fertility and even child mortality rates (Iyigun and Walsh 2007; Eswaran 2002). Interestingly, the theoretical empowerment literature suggests that the determinants of empowerment within a relationship are to a large extent shaped earlier in life. Some empirical evidence suggests that women's bargaining power increases with resources she brought in when she retains ownership of those assets during her marriage (Thomas, Contreras, and Frankenberg 2002) and when she is equal given property rights (Field 2007). Recent research finds positive impacts on adult life outcomes from child sponsorship programs (Wydick, Glewwe, and Rutledge 2013) and a potential mechanism may be higher levels of self-esteem, educational and occupational aspirations (Glewwe, Ross and Wydick 2013). Hence, theory and some empirical evidence suggests that influencing the resources and agency of females at a young age may lead to improved outcomes in the future - privately and socially. Our study adds to this literature by summarizing the short-term effects of a two-year cash transfer intervention targeted explicitly at never-married females on a broad set of outcomes related to empowerment.

Our discussion first focuses on empowerment impacts of CCTs, before turning to a brief comparison of them with UCTs. The reason for this approach is that the CCT experiment was conducted in two strata - girls who were in school at baseline (baseline schoolgirls) and girls who had already dropped out of school at baseline (baseline dropouts). The UCT intervention, on the other hand, was only conducted amongst baseline schoolgirls. Previous studies evaluating the impact of the ZCTP focused mostly on baseline schoolgirls, as this group allowed an experimental comparison of impacts between the CCT and the UCT arms of the intervention (see Baird, McIntosh and Özler 2011). However, CCTs had large and statistically significant impacts on a number of outcomes among baseline dropouts as well - a group that is often left out of programs that are school-based (Bandiera et al. 2012). Thus, we first present findings on the impacts of CCTs for both baseline schoolgirls and baseline dropouts, before turning to a 
comparison of CCT and UCT impacts among baseline schoolgirls only. ${ }^{7}$ We examine impacts while the program was ongoing (Round 2) and immediately after the program ended (Round 3).

When examining the effects of CCTs on female empowerment, we focus on baseline schoolgirls and baseline dropouts separately throughout the analysis for a number of reasons. First, the schooling condition works differently on these two groups - for baseline dropouts it brings them back into school, while for baseline schoolgirls it prevents them from dropping out. Second, as described in Section 3 below, these groups look vastly different across a host of baseline characteristics and thus are best viewed as separate populations. Finally, baseline dropouts are a group that is often ignored in the analysis of CCT programs even though the size of this population is non-negligible. Thus, we feel that providing results separately for this group may provide the reader with some important insights.

The remainder of this paper proceeds as follows. Section 2 describes the cash transfer intervention and the experimental design of this study. Section 3 discusses the estimation strategy. Section 4 presents the main results for the CCT arm and focuses on program impacts on the dimensions of resources, agency and functioning, with section 5 discussing the results for the UCT arm and comparing the two interventions. Section 6 concludes.

\section{Research Setting AND DeSign 8 \\ Location}

Malawi, the setting for this research project, is a small and poor country in southern Africa. $81 \%$ of its population of 15.3 million lived in rural areas in 2009, with most people relying on subsistence farming. The country is poor even by African standards: Malawi's 2008

\footnotetext{
${ }^{7}$ The decision to leave the discussion of the impact of UCTs until after the discussion of CCTs is not a reflection on the relative importance of these two interventions. It is simply for ease of exposition -- allowing for an explicit focus on baseline dropouts.

${ }^{8}$ This section draws heavily from section 2 in Baird, McIntosh, and Özler (2011), which provides more detail on the study design and the intervention.
} 
GNI per capita figure of $\$ 760$ (PPP, current international \$) is less than $40 \%$ of the sub-Saharan African average of \$1,973 (World Development Indicators Database, 2010).

\section{Sample}

Zomba District in the Southern region was chosen as the site for this study. Zomba District is divided into 550 enumeration areas (EAs), which are defined by the National Statistical Office of Malawi and contain an average of 250 households spanning several villages. Fifty of these EAs lie in Zomba city, while the rest are in seven traditional authorities. Prior to the start of the experiment, 176 EAs were selected from three different strata: Zomba city (urban, 29 EAs), near rural (within a $16 \mathrm{KM}$ radius of Zomba city, $119 \mathrm{EAs}$ ), and far rural (28 EAs). In these 176 EAs, each dwelling was visited to obtain a full listing of never-married females, aged 13-22. ${ }^{9}$ The target population was then divided into two main groups: baseline dropouts and baseline schoolgirls. In each selected EA, $100 \%$ of all eligible baseline dropouts and 14\%-100\% of all eligible baseline schoolgirls were randomly sampled to participate in the study, where the percentage depended on the core respondent's age at baseline and the strata she lived in (urban, near rural and far rural). This sampling procedure resulted in a total study sample of 3,796 women with an average of 5.1 baseline dropouts and 16.5 baseline schoolgirls per EA.

\section{Research Design}

Treatment status was assigned at the EA level and the sample of 176 EAs was randomly divided into two equally sized groups: 88 treatment EAs and 88 control EAs. In the 88 treatment EAs, all baseline dropouts were offered conditional cash transfers. The 88 treatment EAs were then randomly assigned to one of three groups to determine the treatment status of baseline schoolgirls: in 46 EAs baseline schoolgirls received transfer offers conditional on regular school

\footnotetext{
${ }^{9}$ The target population of 13-22 year-old, never-married females was selected for a variety of reasons. For details, we refer the reader to Baird, McIntosh, and Özler (2011).
} 
attendance (CCT arm), while in 27 EAs they received offers for unconditional cash transfers (UCT arm). In the remaining 15 EAs no baseline schoolgirls received any transfer offers. ${ }^{10}$

\section{CCT Intervention}

After the random selection of EAs and individuals into the treatment group, the local NGO retained to implement the cash transfers held meetings in each treatment EA between December 2007 and early January 2008 to invite the selected individuals to participate in the program. At these meetings, the program beneficiary and her parents/guardians were made an offer that specified the monthly transfer amounts being offered to the beneficiary and to her parents, the condition to regularly attend school, and the duration of the program. It was possible for more than one eligible girl from a household to be invited to participate in the program.

The offer to participate in the program consisted of a transfer to the parents, a transfer directly to the girl, and payment of school fees for girls attending secondary school. Transfer amounts to the parents were varied randomly across EAs between $\$ 4, \$ 6, \$ 8$, and $\$ 10$ per month, so that each parent within an EA received the same offer. Within each EA, a lottery was held to determine the transfer amount to the young female program beneficiaries, which was equal to $\$ 1$, $\$ 2, \$ 3, \$ 4$, or $\$ 5$ per month. The lottery was held publicly to ensure that the process was transparent. ${ }^{11}$ Secondary school fees were paid in full directly to the schools. ${ }^{12}$ This paper focuses on the average effect of these transfers and does not delve into elasticities of the outcomes under investigation with respect to the transfer amounts.

Monthly school attendance of all the conditional cash transfer recipients was checked and payment for the following month was withheld for any student whose attendance was below $80 \%$

\footnotetext{
${ }^{10}$ Girls who live in treatment EAs but do not receive transfers allow for the measurement of spillover effects within treatment EAs.

11 The lottery was held among those selected to participate in the program. Hence, each girl present at the lottery was offered at least $\$ 1 /$ month individually and $\$ 4 /$ month for her parents. Girls not selected for the program were never contacted by the implementing NGO and were not present at the lottery.

${ }^{12}$ Primary schools are free in Malawi, but student have to pay non-negligible school fees at the secondary level. The program paid these school fees for students in the conditional treatment arm upon confirmation of enrollment for each term. Private secondary school fees were also paid up to a maximum equal to the average school fee for public secondary schools in the study sample.
} 
of the number of days that the school was in session for the previous month. However, participants were never removed from the program for failing to meet the monthly $80 \%$ attendance rate meaning that if they subsequently had satisfactory attendance, their payments would resume. Offers to everyone, identical to the previous ones they received, and regardless of their schooling status during the first year of the program in 2008, were renewed between December 2008 and January 2009 for the second and final year of the intervention, which ended at the end of 2009.

\section{UCT Intervention}

In the UCT EAs, the offers were identical with one crucial difference: there was no requirement to attend school to receive the monthly cash transfers. Other design aspects of the intervention were kept identical so as to be able to isolate the effect of imposing a schooling conditionality on primary outcomes of interest. ${ }^{13}$ Attendance was never checked for recipients in the UCT arm and they received their payments by simply presenting at the transfer locations each month.

\section{Data}

The data used in this paper were collected in three household survey rounds. Baseline data, or Round 1, was collected between October 2007 and January 2008, before the offers to participate in the program took place. First follow-up data collection, or Round 2, was conducted approximately 12 months later - between October 2008 and February 2009. The second followup (Round 3) data collection was conducted between February and June 2010 - after the

\footnotetext{
${ }^{13}$ For households with girls eligible to attend secondary schools at baseline, the total transfer amount was adjusted upwards by an amount equal to the average annual secondary school fees paid in the conditional treatment arm. This additional amount ensured that the average transfer amounts offered in the CCT and UCT arms were identical and the only difference between the two groups was the "conditionality" of the transfers on satisfactory school attendance.
} 
completion of the two-year intervention at the end of 2009. The intervention period coincided with the 2008 and 2009 school years. ${ }^{14}$

The annual household survey consisted of a multi-topic questionnaire administered to the households in which the sampled respondents resided. It consisted of two parts: one that was administered to the head of the household and the other administered to the core respondent, i.e. the sampled girl from our target population. The former collected information on the household roster, dwelling characteristics, household assets and durables, shocks and consumption. The survey administered to the core respondent provides detailed information about her family background, schooling status, health, dating patterns, sexual behavior, fertility, and marriage. In addition to the household survey, biological data on HIV and Herpes Simplex Virus-2 (HSV-2) were collected 18 months after baseline (approximately 6 months after the Round 2 household survey). ${ }^{15}$ Finally, the entire sample was given three achievement tests (Mathematics, English Reading Comprehension, and Raven's Colored Matrices), conducted at home, in Round 3.

\section{ESTIMATION STRATEGY}

\subsection{Attrition ANd BALANCE}

Before turning to our overall estimation strategy, this sub-section first examines two potential sources of bias: (i) differential attrition and (ii) imbalance in baseline characteristics between treatment and control. Table 1 investigates attrition by regressing a binary indicator that takes on the value of one if a respondent was surveyed in all three rounds on the treatment indicator. Column (1) shows that among baseline dropouts the attrition rate in the control group was $\mathbf{1 5 . 7 \%}$ with no significant difference between treatment and control. Column (2) shows that among baseline schoolgirls, the attrition rate among the control group was even lower at 10.7\%, with again no significant differences between either treatment arm and the control group, nor

\footnotetext{
${ }^{14}$ At the time of the intervention the Malawian school year corresponded with the calendar year.

${ }^{15}$ See Baird et al. (2012) for more details.
} 
between the two treatment arms $(\mathrm{p}=0.797)$. These findings suggest that the results we present in this paper are unlikely to be biased due to differential attrition between the study arms.

Table 2 investigates the balance of the experiment by regressing baseline covariates (including parental, personal, and household characteristics) that the literature suggests are correlated with outcomes of interest on treatment indicators. Column (1) presents the mean value of each of the baseline characteristics in the control group amongst baseline dropouts, while column (2) presents the coefficient on the difference between treatment and control for baseline dropouts. We observe no violations of balance amongst this group. Column (3) presents the mean in the control for baseline schoolgirls, with column (3) indicating the CCT difference with the control group, column (4) the UCT difference with the control group, and column (5) the p-value for the difference between the two treatment arms. First of all we observe that, on average, baseline schoolgirls come from better socioeconomic backgrounds than baseline dropouts. Baseline schoolgirls have completed more schooling, come from households with better access to durable goods, are more likely to have parents who are still alive, and less likely to be sexually active. There is one violation in baseline balance for the CCT baseline schoolgirls, and one for the UCT arm, with these two variables also being different between the two treatment arms: girls in the CCT arm are approximately half a year younger than those in the UCT arm and, hence, have a similarly low grade attainment at baseline. As described in the sub-section below, we control for the baseline values of these variables in our analysis of program impacts.

\subsection{SPECIFICATION}

We analyze the intention-to-treat (ITT) effects of the intervention separately on Round 2 and Round 3 indicators using cross-sectional regressions. This approach allows us to investigate whether there were any empowering impacts of the program while the young women were still participating in the cash transfer program, as well as whether such impacts were still present immediately after the program ended. The regression-adjusted ITT impact of the program is estimated with Ordinary Least Squares (OLS) using the following linear regression model:

$$
Y_{i}=T_{i}^{C} \gamma^{C}+T_{i}^{U} \gamma^{U}+X_{i} \beta+\varepsilon_{i},
$$


where $Y_{i}$ is the empowerment outcome for individual $i$ in Round 2 or Round 3. $X_{i}$ is a vector that contains a set of baseline controls. $T_{i}^{C}\left(T_{i}^{U}\right)$ is a binary indicator that is equal to one if a girl was offered a CCT (UCT) and zero otherwise. For baseline dropouts, Equation 1 excludes the UCT indicator. The standard errors $\varepsilon_{i}$ are clustered at the EA level to account for the design effect of the EA-level treatment assignment. Age- and stratum-specific sampling weights are used to make the results representative of the target population in the study area. To make the results comparable across survey rounds, the analysis includes respondents if and only if they were interviewed in all three rounds.

In choosing the covariates, $X_{i}$, included in this analysis, we follow the approach advocated by Bruhn and McKenzie (2009) and control for two types of variables: strata that were used for block randomization in the trial and baseline characteristics that are predictive of the outcome. In this study, these covariates include dummy variables for age and geographic strata along with an index of household assets, highest grade attained, and sexual activity status - all measured at baseline.

\section{IMPACTS OF CCTS}

\subsection{RESOURCES}

We first investigate to what extent the ZCTP influenced the physical resources available to the core respondent. As explained above, the monthly transfers consisted of two components, one component paid to the parents (or the guardian) of the core respondent and one component paid directly to the core respondent herself. Table 3 examines whether the cash transfers translated into higher monthly expenditures by respondents on themselves. Columns (1)-(2) presents the impacts in Round 2 (during the intervention) while columns (3)-(4) present impacts in Round 3 (after the intervention ended).

Baseline dropouts spent US\$1.5 a month more than the control group while the program was ongoing, an increase of approximately $42 \%$ (column 1). This increase amounts to approximately half of the mean amount of US $\$ 3 /$ month transferred directly to the respondents. The increase in expenditures was similar for baseline schoolgirls at US\$1.8 per month, an 
increase of approximately $80 \%$ over the control group (column 2). The impact of the program remained after the program ended for baseline schoolgirls, although the magnitude had declined by over $50 \%$ with no significant effect among baseline dropouts. The results suggest that the cash transfer program led to an increase in the beneficiaries' control of cash resources during the program, and that these impacts declined or disappeared shortly after the end of the program.

Table 4 shows that the direct transfers to the beneficiaries most likely drove this increase in personal consumption. Panel A shows that respondents had little influence on the way the component paid to the household was spent. Roughly $90 \%$ of the respondents indicated that the decision on how to spend these funds was made by someone else. Panel B, on the other hand, shows that approximately $80 \%$ of the young female beneficiaries had control over how to spend the transfers made directly to them. ${ }^{16}$

\subsection{AgenCY}

\subsubsection{SCHOOLING}

Next, we turn to the impact of the intervention on social patterns that can be detrimental to the development of adolescent girls. We first investigate how the intervention affected schooling outcomes. Baird, McIntosh, and Özler (2011) show that the CCT program had a strong effect on school enrollment among baseline schoolgirls. Among this group the intervention significantly increased the average number of terms enrolled by 0.54 according to teacher reports (over a base of 4.79 terms in the control out of a maximum of six during the two academic years the program ran). Baseline dropouts experienced an increase of 2.35 terms (compared to 1.02 in the control

\footnotetext{
${ }^{16}$ This finding accords with findings from focus group interviews at the design stage of ZCTP, during which females eligible for the program indicated that they would be able to "keep their transfers" if these were physically given to them.
} 
group, using self-reported enrollment data - see Appendix Table A, column 1) - an impact that more than tripled the number of terms enrolled. ${ }^{17}$

An important question is whether the program empowered respondents by providing them with additional knowledge and skills to make important life decisions. Baird, McIntosh, and Özler (2011) provide a first indication that the intervention indeed resulted in increased skills. They show that among baseline schoolgirls, there were significant improvements in math, English and cognitive test scores during Round $3 .{ }^{18}$ Among baseline dropouts, there were also modest, but statistically significant improvements across the three tests with impacts ranging from 0.13 standard deviations in English Reading Comprehension $(\mathrm{p}<0.10)$ to 0.16 standard deviations in mathematics $(\mathrm{p}<0.05)$ (Appendix Table A, columns 2-4). Table 5 adds to this evidence by investigating whether the program increased participation in any form of health training (including nutrition, personal hygiene, food hygiene, sexual education, and HIV/AIDS) and shows that both groups of CCT beneficiaries saw increases in the probability of participating in health training during the past 12 months.

\subsubsection{Fertility AND MARriage}

Having shown that the ZCTP improved the physical resources available to respondents and increased their school participation and learning, we now turn to other important outcomes, such as childbearing and marriage, which may be influenced by the intervention either through an income effect or an effect of the condition to regularly attend school. We first investigate the impact of the intervention on respondents' fertility decisions, one of the prime outcomes in the theoretical empowerment literature (see, for instance, Eswaran 2002 or Iyigun and Walsh 2007).

\footnotetext{
${ }^{17}$ We did not collect teacher reports of enrollment or attendance for this stratum in Round 3. Hence, these findings should be treated with some caution due to the fact that the underlying data for school enrollment are self-reported. Please see Baird and Özler (2012) for more on the reliability of self-reported data on school participation. However, significant improvements in learning presented in Appendix Table A support the finding of a significant increase in the re-enrollment rate for this group.

${ }^{18}$ For more details on the specifics of these achievement tests, see Baird, McIntosh and Özler (2011). These tests were only conducted in Round 3.
} 
Baird et al. (2010) shows that the conditional cash transfers significantly reduced pregnancy among treated baseline dropouts during the first year of the program, with no significant impact among baseline schoolgirls. ${ }^{19}$ Baseline dropouts were 5.1 percentage points less likely to ever have been pregnant (61\% in the control group) in Round 2 and 8.2 percentage points (78\% in the control group) in Round 3 (Appendix Table 1, column 5). In Table 6, we investigate whether the program also impacted preferred fertility timing or desired lifetime fertility. Looking at the impact of the intervention on the number of months the respondent would like to wait before having a child, we observe significant increases for baseline dropouts in both rounds and for baseline schoolgirls in Round 3 (columns 1-4). ${ }^{20}$ CCT effects on the ideal number of children are generally negative but only significant among baseline schoolgirls at the end of the intervention, who, on average, want 0.184 less children over their lifetimes. The evidence suggests a desire to delay childbearing as a result of the intervention rather than lowering the ideal number of children.

Turning now to marriage, the CCT program led to a significant decline in marriage rates among baseline dropouts. At baseline all of the respondents were never married, while $28 \%$ of the baseline dropouts in the control group had gotten married by Round 2. In the treated group the marriage rate was 11 percentage points lower (Baird et al. 2010). This difference persisted after the program ended-baseline dropouts were 12.6 percentage points less likely to be married by Round 3 - from a mean of 55.1\% in the control group (Appendix Table A, column 6). Among baseline schoolgirls, on the other hand, there was no evidence of a significant impact of the CCT intervention on marriage during or after the program (Baird, McIntosh and Özler 2011).

\footnotetext{
${ }^{19}$ For an explanation of why a significant effect on childbearing is observed among baseline dropouts but not baseline schoolgirls, please refer to Baird, McIntosh and Özler (2011), pages 1735-40.

${ }^{20}$ This variable is missing for respondents who want zero children or do not want any more children. We find no impact of the intervention on whether or not this variable is missing for baseline dropouts. However, in Round 3, there is a significant and positive coefficient on this relationship for baseline schoolgirls. This result suggests that the CCT intervention may have also decreased the number of respondents wanting any additional children among baseline schoolgirls. The significant decline in the ideal number of children in this same group (Table 6, column 8) supports this interpretation.
} 
It may be puzzling to the reader as to why a large effect on marriage is found among baseline dropouts but not baseline schoolgirls. As discussed in detail in Baird, McIntosh and Özler (2011), the cash transfer effect on marriage works through two channels in Malawi where marriage and schooling are exclusive: an income effect and a schooling effect. In the case of CCTs, the income effect is zero for those who drop out of school during the program because they cease to receive payments. Hence, the primary channel through which CCTs can delay marriage is through increased school enrollment. In this experiment, the marginal effect of CCTs on school enrollment was, while significant, relatively small among baseline schoolgirls, meaning that the knock-on effect on marriage was undetectable. Baseline dropouts on the other hand experienced a massive surge in their odds of re-enrollment, which translated into delayed marriage and pregnancy. The CCT intervention also had a significant impact on baseline dropouts viewing education as an important characteristic of a future spouse (results not shown). We come back to this issue in Section 5, when we contrast the effects of UCTs on these outcomes, where the channels of impacts are different yet again.

Overall, the results presented in this section indicate that CCTs had a strong impact on agency, as they caused beneficiaries to postpone marriage and pregnancy and to increase their school participation and learning. These changes may well affect the wellbeing of these respondents later in life as well as their bargaining power in future relationships. Moreover, as the next section will show, the intervention also had a substantial impact on the contemporary functioning of respondents.

\subsection{FUNCTIONING}

\subsubsection{Position In THE HouSEHOLd}

Finally, we examine how the intervention affected two areas of functioning within the household: (i) self-perceived position within the household, and (ii) nutrition and health. Table 7 first examines how the intervention affected respondents' answer to the question "Would you say your household cares more about your education now compared to 12 months ago?" Baseline dropouts and baseline schoolgirls in the CCT arm are significantly more likely to agree with the statement than those in the control group during the program (columns $1 \& 2$ ); not surprisingly, 
there are no significant changes between Rounds 2 and 3 (columns $3 \& 4$ ). The pattern is the same when we analyze responses to the question "Would you say your household cares more about your health now compared to 12 months ago?" These findings suggest that the intervention may have improved the standing of the school-age beneficiaries within their households perhaps through a norm change in treatment communities regarding the importance of investing in the human capital of girls or simply by making them more of an asset to their families during the program period.

\subsubsection{NUTRITION AND HEALTH}

Above, we showed that beneficiaries perceived their households' to care more about their health while the program was ongoing. We now look at whether this perception is accompanied by tangible improvements in investments in nutrition and health, as well as measurable health outcomes. Kabeer (1999) argues that nutrition and health outcomes are prime examples of "universally valued functionings" and as such they are highly relevant empowerment outcomes.

In Table 8, we first look at the impact of the intervention on the intake of three sources of protein: meat, eggs, and fish (columns 1-4). The outcome variable counts the number of days respondents ate any of these three items over the seven days prior to the interview. ${ }^{21} \mathrm{We}$ find that CCTs caused a modest increase (approximately 10\%) in the consumption of protein rich food items among both baseline dropouts and baseline schoolgirls during the program (columns $1 \&$ 2) and that this effect persisted among baseline schoolgirls after the program ended, with no such lasting effect among baseline dropouts (columns $3 \& 4$ ). We then investigate whether the intervention affected the probability that respondents usually sleep under a bed net (columns 5-8). We observe a significant improvement among baseline schoolgirls: they are $7.8 \%(8.5 \%)$ percentage points more likely to sleep under a bed net in Round 2 (Round 3) - representing a large increase compared to the control group mean of $49.3 \%$ (65.9\%). Given the high prevalence of malaria parasitemia in this area, which is a frequent cause of school absenteeism, it makes

\footnotetext{
21 This variable thus takes values from 0 to 21: 0 if the respondent ate none of these food items and 21 if the respondent ate all of the ingredients every day during the seven days prior to the interview.
} 
sense for families to devote resources to preventive health measures in an effort to minimize the probability of missing transfer payments due to non-compliance. These findings are also consistent with the effects of CCTs on school attendance being highest during Term 1, when the number of malaria cases reaches its peak in Malawi (Baird, McIntosh, and Özler 2011). We observe no similar improvements among baseline dropouts during or after the program. This is somewhat surprising, but it is worth noting that baseline dropouts come from significantly poorer households than baseline schoolgirls.

There is also evidence that the intervention improved the mental health of its beneficiaries - at least during the two-year period while it was ongoing. Using the General Health Questionnaire 12, a screening instrument widely used in clinical settings to detect individuals who are likely to suffer from psychological distress, Baird, de Hoop, and Özler (2013) show that baseline schoolgirls in the CCT arm were approximately 6 percentage points (or 17\%) less likely to be suffering from psychological distress than those in the control group during the program. These effects had become smaller and statistically insignificant soon after the program ended. No similar effects were detected among baseline dropouts. The authors suggest that the significant changes in the daily life of baseline dropouts due to reenrollment in school compared with the relative lack of such changes among baseline schoolgirls may partly explain the differential impact of the intervention on the psychological wellbeing of adolescents in these two strata.

Together, the presented results suggest that the impact of the intervention differed substantially between baseline schoolgirls and baseline dropouts. We observe stronger effects on health and nutrition among baseline schoolgirls and larger changes in marriage, pregnancy, and school enrollment among baseline dropouts. A likely explanation for this finding lies in the baseline differences between these two strata and the actions that needed to be taken by the beneficiaries and their households to ensure compliance with the condition to attend school regularly. As we saw earlier, pregnancy and marriage are much bigger hazards to school enrollment among baseline dropouts, so their households would have encouraged beneficiaries not to get married or pregnant, to spend more time attending school and less time on household chores and labor. In the households of baseline schoolgirls, the potential payoff from following this strategy was limited because the children were already spending a relatively large share of 
their time on schooling - i.e. most of the transfers to baseline schoolgirls were infra-marginal. These households are more likely to decrease the probability of non-compliance by investing in the health of their eligible children to minimize school absences due to illness.

\section{IMPACTS OF UCTS}

Previous analysis contrasted the effects observed in the CCT and the UCT arms on schooling outcomes, marriage, pregnancy, and mental health among baseline schoolgirls (Baird, McIntosh, and Özler 2011); Baird, de Hoop and Özler 2013). These papers report some interesting findings, which suggest that attaching conditions to cash transfers have costs and benefits. For example, while the UCT program significantly reduced the dropout rate among its beneficiaries, this impact was only $43 \%$ as large as the impact of the CCT arm at the end of the two-year program. Moreover, as confirmed by differential impacts on attendance and test scores favoring the CCT arm, CCTs were found to be more cost-effective than UCTs in raising enrollment rates. However, as discussed above, while the CCT program had no impact on marriage and pregnancy among baseline schoolgirls, the UCT treatment led to a significant reduction on both marriage and pregnancy by the end of the program. Furthermore, while both programs caused significant declines in psychological distress while the program was ongoing, the effects in the UCT arm were significantly larger than those in the CCT arm.

Baird, McIntosh, and Özler (2011) provide an explanation for the differential effects of CCTs and UCTs on marriage and pregnancy. While CCTs only had an indirect effect on these outcomes through their effect on increased schooling participation, UCTs had a direct effect on marriage and pregnancy through an income effect. This difference between the two study arms was due almost entirely to the effect of UCTs among girls who dropped out of school during the two-year program - as this large group of girls still received regular transfer payments. The authors argue that schooling conditions, while effective in improving school participation and learning, may undermine the social protection aspect of cash transfer programs by denying support to non-compliant households.

Baird, de Hoop and Özler (2013) exploit the random variation in amounts that were transferred separately to the girls and their parents (guardians) in each study arm and find that 
CCT and UCT effects on mental health were similar at the lowest amounts given to the households. However, increasing transfers to parents conditional on school attendance by the beneficiary led to significant increases in psychological distress of the adolescent girls - no such gradient was found in the UCT arm or for the transfers to the girls. The authors speculate that the burden of becoming the main source of income for their families may have become too much for these school-aged children to shoulder when a large monthly transfer was conditional on their actions.

The new results presented in this paper provide some additional insights to these earlier findings. With respect to resources, like the CCT arm, the UCT arm significantly increased the personal consumption of the respondent while the program was ongoing, but this impact appears to have dissipated faster than that of the CCT arm (Table 3). The UCT recipients also report controlling the transfer that was directly transferred to them $(86 \%)$, with very few controlling the household level transfer (5\%). Thus, these results suggest that the cash transfer program led to an increase in the control of resources for the UCT beneficiaries during the program, but that the effect did not last once the program ended. In terms of agency, unlike the CCT arm, we find no impacts of UCTs on either the number of months before having their next child or the ideal number of children (Table 6), and these effects differ from the CCT arm ( $\mathrm{p}=0.100$ and $\mathrm{p}=0.119$, respectively). Given the significantly larger delays in fertility among this group, it will be interesting to see whether the pregnancy and marriage rates in the UCT arm quickly catch up with the CCT arm in the near future. Finally, turning to functionings, respondents in the UCT arm report similar or larger effects on their self-perceived standing within their households (Table 7), similar increases in the consumption of food items rich in protein, but a lower likelihood of sleeping under bed nets (Table 8). Income effects likely explain the improvements in their position within the household and increases in their personal and food consumption, while the lack of incentives to attend school is consistent with the lack of effect in preventive health investments, such as bed nets.

These findings make clear that the impacts of CCT and UCT programs are likely to differ - at least in the short-run - and that one is not clearly preferable to the other. The choice between these two approaches may depend on the aims of the intervention, the target population, and 
relative weights the policymaker or the social planner assigns to various outcomes. This is of course only true under the assumption that there is a legitimate reason to attach conditions to cash transfer programs, such as market failures, externalities, or political economy reasons. Furthermore, it is not clear how these short-term impacts might translate into longer-term outcomes with respect to women's empowerment. It will be interesting to observe whether there are longer-term impacts on a broad range of outcomes, such as subjective welfare, bargaining power within marriages, fertility choices, early childhood development of own children, labor force participation, voice and political participation, etc. and whether and how these differ between the experimental study arms.

\section{Concluding Discussion}

Adolescent girls in developing countries are considered to be an important target group for policymakers. Targeted interventions for this group may not only affect their welfare directly, but they also have the potential to bring benefits to future generations. This paper investigates whether one such intervention, the Zomba Cash Transfer Program in Malawi, helped empower adolescent girls in the short-run. Summarizing evidence from multiple papers examining the impacts of this program on a broad range of outcomes and providing some new analysis here, this paper suggests that the answer is a clear 'yes.' The program effectively increased access to financial resources, increased schooling outcomes, decreased teen pregnancies and early marriages, improved health, and generally enabled beneficiaries to improve their agency within their households.

The intervention provided its beneficiaries with financial support conditional on attending school in the CCT arm, and unconditionally in the UCT arm. Furthermore, the CCT arm was targeted to two distinct groups of school-age girls: those that were in school at baseline and those that had already dropped out before the intervention began. The latter group, albeit small at approximately $15 \%$ of the eligible population, saw substantial increases in schooling outcomes, as well as large declines in early marriage and pregnancy rates. As many interventions targeting school-aged populations are school-based, these findings point to the importance of conducting population-based interventions to avoid exclusion of this particularly vulnerable group of young people. 
The CCT program changed some common socioeconomic patterns that affect young women in Malawi, as it induced beneficiaries to delay childbearing and marriage. There is some evidence that these changed socioeconomic patterns are accompanied with changed marital and fertility preferences, suggesting that empowering adolescent women may not only increase their bargaining power within future relationships, but it may also affect the type of relationship they enter into in the first place. The experiment also revealed contrasting findings between the CCT and the UCT arms. While eligible girls in both arms experienced benefits, the domains in which they experienced these benefits and the strength of the effects differed between the two groups. The findings teach us that while there may be good reasons to implement CCT programs, there are serious tradeoffs associated with attaching conditions to cash transfer programs. The design choice will depend on the target population and the goals at hand.

Overall, the results presented here indicate that cash transfers targeted at adolescent girls and young women can empower them in significant ways in the short-run - at least in this or similar settings. It can alter social patterns that cause sub-optimal investments in the human capital of young women and it can improve both their standing within the household and their day-to-day functioning. While these short-run impacts are promising, the ultimate impact of the ZCTP will depend on whether this relatively short (two-year) cash transfer program - introduced at a particularly important period of transition from adolescence to adulthood - can have longlasting effects on the lives of this cohort of young females and their future families. 


\section{REFERENCES}

Ashraf, N., E. Field, and J. Lee (2012). "Household Bargaining and Excess Fertility: An Experimental Study in Zambia."

http://www.people.hbs.edu/nashraf/papers/AshrafFieldLeeManuscript-12-16-12.pdf. Accessed on July 30, 2013.

Baird, S., E. Chirwa, C. McIntosh, and B. Özler (2010). "The Short-term Impacts of a Schooling Conditional Cash Transfer Program on the Sexual Behavior of Young Women." Health Economics, 19, 55-68.

Baird, S., J. de Hoop, and B. Özler. (2013). "Income Shocks and Adolescent Mental Health," Journal of Human Resources, 48 (2), pp. 370-403.

Baird, S., R. Garfein, C. McIntosh, and B. Özler. (2012). "Effect of a cash transfer programme for schooling on prevalence of HIV and herpes simplex type 2 in Malawi: a cluster randomised trial," The Lancet, 379(9823), pp. 1320-1329.

Baird, S., C. McIntosh, and B. Özler. (2011). "Cash or Condition? Evidence from a Cash Transfer Experiment", Quarterly Journal of Economics, 126 (4), pp. 1709-1753.

Baird, S. and B. Özler (2012), "Examining the Reliability of Self-Reported Data on School Participation," Journal of Development Economics, Vol. 98(1), pp. 89-93.

Bandiera, O., N. Buehren, R. Burgess, M. Goldstein, S. Gulesci, I. Rasul, and M. Sulaiman (2012). "Empowering Adolescent Girls: Evidence from a Randomized Control Trial in Uganda." http://www.ucl.ac.uk/ uctpimr/research/ELA.pdf. Accessed on September 3, 2013.

Barber, S. L. and P. J. Gertler (2010). “Empowering Women: How Mexico's Conditional Cash Transfer Programme Raised Prenatal Care Quality and Birth Weight." Journal of Development Effectiveness, 2 (1), 51-73.

Boden, J. M., D. M. Fergusson, and L. J. Horwood (2007). "Early Motherhood and Subsequent Life Outcomes." Journal of Child Psychology and Psychiatry, 49 (2), 151-160.

Bruhn, M., and D. McKenzie (2009). "In Pursuit of Balance: Randomization in Practice in Development Field Experiments." American Economic Journal: Applied Economics, 1(4): 200-232.

Chen, X, S. Wu Wen, N. Fleming, K. Demissie, G. G. Rhoads, and M. Walker (2007). “Teenage Pregnancy and Adverse Birth Outcomes: A Large Population Based Retrospective Cohort Study." International Journal of Epidemiology.

Chiappori, P., M. Iyigun, and Y. Weiss (2009). "Investment in Schooling and the Marriage Market." American Economic Review, 99 (5), 1689-1713. 
Chiappori, P. and S. Oreffice (2008). "Birth Control and Female Empowerment: An Equilibrium Analysis.” Journal of Political Economy, 116 (1), 113-140.

Dercon, S., and P. Krishnan (2000). "In Sickness and in Health: Risk Sharing within Households in Rural Ethiopia." Journal of Political Economy, 108 (4), 688-727.

Duflo, E. (2012). "Women Empowerment and Economic Development." Journal of Economic Literature, 50 (4), 1051-1079.

Duflo, E. (2003). "Grandmothers and Granddaughters: Old-Age Pensions and Intrahousehold Allocation in South Africa.” World Bank Economic Review, 17 (1), 1-25.

Edmonds, E. V. (2006). "Child Labor and Schooling Responses to Anticipated Income in South Africa." Journal of Development Economics 81 (2), 386-414.

Eswaran, M. (2002). “The Empowerment of Women, Fertility, and Child Mortality: Towards a Theoretical Analysis." Journal of Population Economics, 15, 433-454.

Gage, A. (2000). "Female Empowerment and Adolescent Demographic Behaviour," in Harriet B. Presser and Gita Sen (eds.), Women's Empowerment and Demographic Processes: Moving Beyond Cairo. Oxford: Oxford University Press.

Gage, A. (1998). "Sexual Activity and Contraceptive Use: The Components of the Decisionmaking Process."Studies in Family Planning, 29(2), pp. 154-166.

Gilbert, W., D. Jandial, N. Field, P. Bigelow, and B. Danielson (2004). "Birth Outcomes in Teenage Pregnancies.” Journal of Maternal-Fetal and Neonatal Medicine, 16 (5), 265-270.

Glewwe, P., P.H. Ross, and B. Wydick (2013). "Developing Aspirations: The Impact of Child Sponsorship on Self-Esteem and Life Expectations." http://www.younglives.org.uk/files/others/inequalities-conference-papers/wydick-glewweross-impactchildsponsorshipself-esteem-lifeexpectations. Accessed on September 5, 2013.

Holland, J., C. Ramazanoglu, S. Scott, S. Sharpe and R. Thomson (1992).” Risk, Power and the Possibility of Pleasure: Young Women and Safer Sex." AIDS Care: Psychological and Socio-medical Aspects of AIDS/HIV. 4(3):273-283.

Hotz, J. V., C. H. Mullin, and A. G. Sanders (1997). "Bounding Causal Effects Using Data from a Contaminated Natural Experiment: Analyzing the Effects of Teenage Childbearing." Review of Economic Studies, 64 (4), 575-603.

Iyigun, M. and R. P. Walsh (2007). "Endogenous Gender Power, Household Labor Supply and the Demographic Transition.” Journal of Development Economics, 82, 138-155.

Kabeer, N. (1999). "Resources, Agency, Achievements: Reflections on the Measurement of Women's Empowerment." Development and Change, 30, 435-464. 
Kandpal, E., K. Baylis, and M. Arends-Kuenning. (2013). "Measuring the Effect of a Community-level Program on Women's Empowerment Outcomes: Evidence from India", The World Bank, Policy Research Working Paper No. 6399.

Karlan, D., N. Ashraf, and W. Yin (2007). "Female Empowerment: Impact of a Commitment Savings Product in the Philippines." World Development, 38 (3), 333-344.

LeGrand, T. K. and C. S. M. Mbacké (1993). "Teenage Pregnancy and Child Health in the Urban Sahel." Studies in Family Planning, 24 (3), 137-149.

Levine, J. A., H. Pollack, and M. E. Comfort (2004). “Academic and Behavioral Outcomes Among the Children of Young Mothers." Journal of Marriage and Family, 63 (2), 355-369.

Levine, R., C.B. Lloyd, M. Greene, and C. Grown (2008). "Girls Count: A Global Investment and Action Agenda.” Reprint, 2009. Washington, D.C.: Center for Global Development.

Lloyd, C. B. (2009). New Lessons: The Power of Educating Adolescent Girls, The Population Council.

Luke, N. (2003). "Age and Economic Asymmetries in the Sexual Relationships of Adolescent Girls in Sub-Saharan Africa." Studies in Family Planning 34(2), 67-86.

Lundberg, S., R. A. Pollak, and T. J. Wales (1997). "Husbands and Wives Pool Their Resources? Evidence from the United Kingdom Child Benefit.” Journal of Human Resources 32 (3), 463-80.

Muralisharan, K. and N. Prakash. (2013). "Cycling to School: Increasing Secondary School Enrollment for Girls in India." Unpublished Manuscript.

Pitt, M. M., S. R. Khandker, and J. Cartwright (2006). "Empowering Women with Micro Finance: Evidence from Bangladesh.” Economic Development and Cultural Change, 54 (4) 791-831.

Rangel, M. A. (2006). “Alimony Rights and Intrahousehold Allocation of Resources: Evidence from Brazil.” Economic Journal, 116 (513), 627-658.

Sen (1999). Development as Freedom, Oxford University Press, Oxford UK.

Ssewamala F.M, L. Ismayilova, M. McKay, E. Sperber, W. Bannon Jr, and S Alicea (2010). "Gender and the Effects of an Economic Empowerment Program on Attitudes Toward Sexual Risk-taking among AIDS-orphaned Adolescent Youth in Uganda.” Journal of Adolescent Health. 46 (4), 372-378.

Warhurst, A., E. Molyneux, and R. Jackson (2010). "Girls Discovered: Global Maps of Adolescent Girls.” http://www.girlsdiscovered.org/ (accessed July 2010). 
Wydick, B., Glewwe, P., Rutledge, L. (2013). "Does International Child Sponsorship Work? A Six Country Study on Impacts on Adult Life Outcomes", Journal of Political Economy, 121 (2), 393-426.

World Development Indicators Database. 2009. Accessed January 2010. 
Table 1: Analysis of Attrition

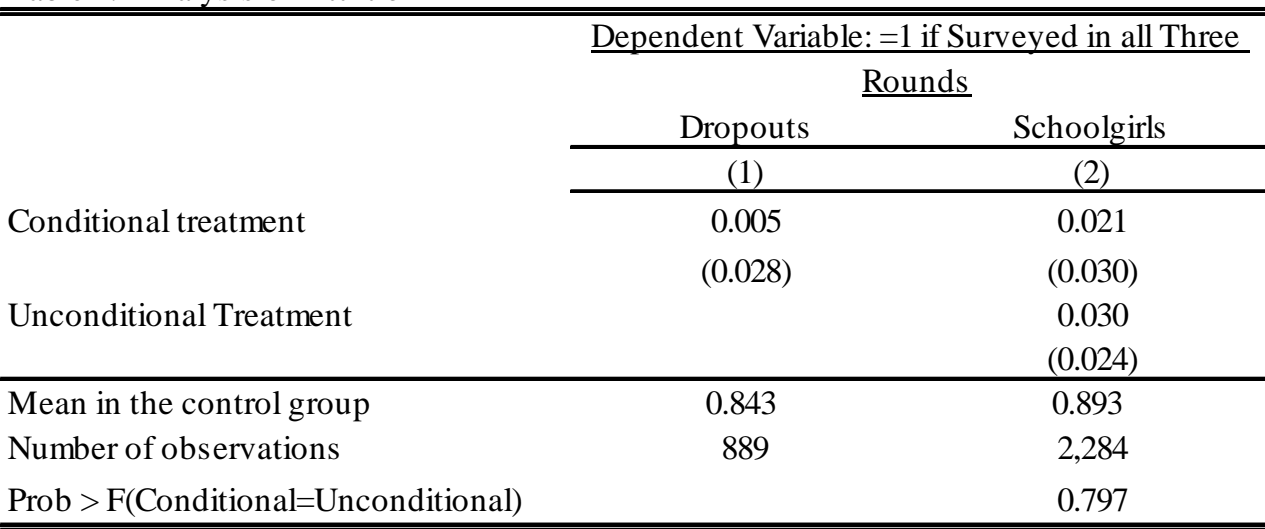

Notes: Regressions are OLS models with robust standard errors clustered at the EA level.

All regressions are weighted to make them representative of the target population in the study EAs. Parameter estimates statistically different than zero at $99 \%(* * *), 95 \%(* *)$, and $90 \%(*)$ confidence. 
Table 2: Balance of baseline characteristics

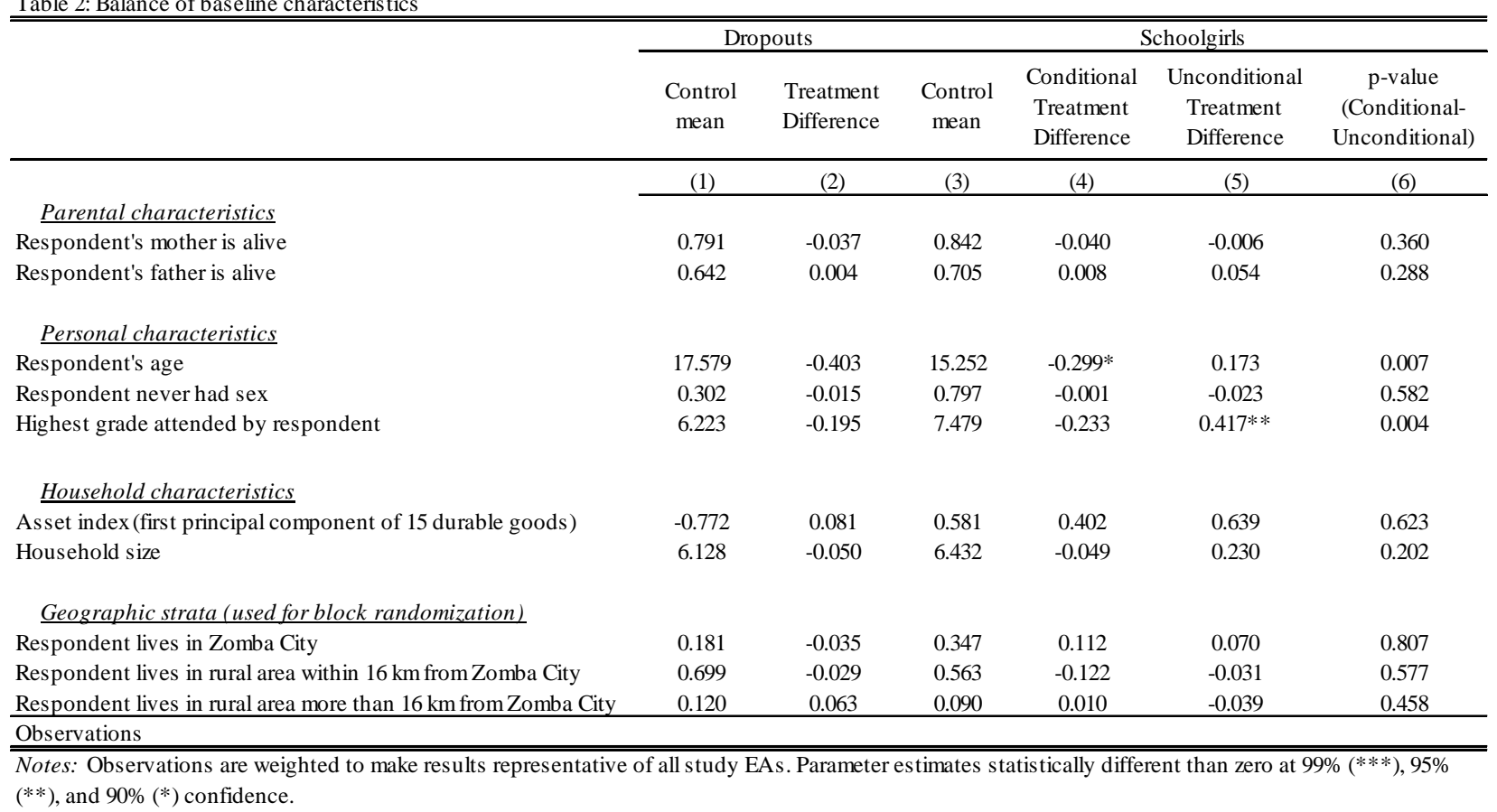


Table 3:Program impacts on expenditure by the respondents on themselves (in USD) over the past 30 days

\begin{tabular}{lcc|cc}
\hline \hline & \multicolumn{2}{c|}{ Round 2 } & \multicolumn{2}{c}{ Round 3 } \\
\hline & Dropouts & Schoolgirls & Dropouts & Schoolgirls \\
\cline { 2 - 5 } Conditional Treatment & $(1)$ & $(2)$ & $(3)$ & $(4)$ \\
\cline { 2 - 5 } & $1.530^{* * *}$ & $1.799^{* * *}$ & 0.334 & $0.788^{* *}$ \\
Unconditional Treatment & $(0.573)$ & $(0.497)$ & $(0.544)$ & $(0.324)$ \\
& & $1.434^{* * *}$ & & -0.229 \\
& & $(0.528)$ & & $(0.885)$ \\
\hline Mean in the control group & 3.593 & 2.263 & 3.740 & 2.488 \\
Number of observations & 750 & 2,087 & 749 & 2,086 \\
Prob > F(Conditional=Unconditional) & & 0.619 & & 0.276 \\
\hline \hline
\end{tabular}

Notes: Regressions are OLS models with robust standard errors clustered at the EA level. All regressions are weighted to make them representative of the target population in the study EAs. Baseline values of the following variables are included as controls in the regression analyses: age dummies, strata dummies, household asset index, highest grade attended, and an indicator for never had sex. Parameter estimates statistically different than zero at $99 \%(* * *), 95 \%(* *)$, and $90 \%(*)$ confidence. 
Table 4: Who decides how the transfer is spent (in percentages)?

\begin{tabular}{lccc}
\hline \hline & Dropouts & $\begin{array}{c}\text { Conditional } \\
\text { Schoolgirl }\end{array}$ & $\begin{array}{c}\text { Unconditional } \\
\text { Schoolgirl }\end{array}$ \\
\cline { 2 - 4 } & $(1)$ & $(2)$ & $(3)$ \\
\cline { 2 - 4 } Panel A: Transfer to household & & & \\
Father & 10.09 & 11.02 & 7.64 \\
Mother & 55.05 & 59.70 & 64.23 \\
Self & 13.76 & 6.77 & 4.96 \\
Other & 21.10 & 22.52 & 23.18 \\
& & & \\
Panel B: Transfer to respondent & & & \\
Father & 3.37 & 2.77 & 0.81 \\
Mother & 11.66 & 13.70 & 7.08 \\
Self & 80.98 & 77.51 & 86.01 \\
Other & 3.99 & 6.02 & 6.10 \\
\hline Number of observations & 326 & 448 & 253 \\
\hline \hline Notes: These results are from Round 2 only. Obs ervations are weighted to make \\
results representative of all study EAs. These results are for treatment girls only
\end{tabular}


Table 5: Program impacts on participation in health training over the past 12 months

\begin{tabular}{lcccc}
\hline \hline & \multicolumn{4}{c}{ Any } \\
\cline { 2 - 5 } & \multicolumn{3}{c}{ Round 2 } & \multicolumn{2}{c}{ Round 3 } \\
\cline { 2 - 5 } & Dropouts & Schoolgirls & Dropouts & Schoolgirls \\
\cline { 2 - 5 } Conditional Treatment & $0.152^{* * *}$ & -0.041 & 0.025 & $0.071^{* *}$ \\
& $(0.041)$ & $(0.029)$ & $(0.034)$ & $(0.033)$ \\
Unconditional Treatment & & 0.012 & & $0.068^{* *}$ \\
Mean in the control group & & $(0.035)$ & $0.035)$ \\
\cline { 2 - 5 } Number of observations & 0.547 & 0.879 & 0.670 & 0.775 \\
Prob > F(Conditional=Unconditional) & 750 & 2087 & 749 & 2086 \\
\hline \hline & & & & 0.939 \\
\hline
\end{tabular}

Notes: Regressions are OLS models with robust standard errors clustered at the EA level. All regressions are weighted to make them representative of the target population in the study EAs. Baseline values of the following variables are included as controls in the regression analyses: age dummies, strata dummies, household as set index, highest grade attended, and an indicator for never had sex. Parameter estimates statistically different than zero at $99 \%(* * *), 95 \%(* *)$, and $90 \%(*)$ confidence. 
Table 6: Program impact on preferred fertility timing or desired life-time fertility.

\begin{tabular}{|c|c|c|c|c|c|c|c|c|}
\hline & \multicolumn{4}{|c|}{ Months Before Next Child } & \multicolumn{4}{|c|}{ Ideal Number of Children } \\
\hline & \multicolumn{2}{|c|}{ Round 2} & \multicolumn{2}{|c|}{ Round 3} & \multicolumn{2}{|c|}{ Round 2} & \multicolumn{2}{|c|}{ Round 3} \\
\hline & Dropouts & Schoolgirls & Dropouts & Schoolgirls & Dropouts & Schoolgirls & Dropouts & Schoolgirls \\
\hline & $(1)$ & (2) & (3) & (4) & $(5)$ & $(6)$ & (7) & $(8)$ \\
\hline Conditional Treatment & $\begin{array}{l}7.383 * * \\
(2.992)\end{array}$ & $\begin{array}{c}4.934 \\
(3.110)\end{array}$ & $\begin{array}{l}3.658^{*} \\
(2.093)\end{array}$ & $\begin{array}{c}9.056 * * * \\
(3.158)\end{array}$ & $\begin{array}{l}-0.064 \\
(0.101)\end{array}$ & $\begin{array}{l}-0.112 \\
(0.104)\end{array}$ & $\begin{array}{c}0.006 \\
(0.086)\end{array}$ & $\begin{array}{l}-0.184^{*} \\
(0.099)\end{array}$ \\
\hline Unconditional Treatment & & $\begin{array}{r}2.790 \\
(3.765) \\
\end{array}$ & & $\begin{array}{r}2.138 \\
(3.130) \\
\end{array}$ & & $\begin{array}{c}0.084 \\
(0.122) \\
\end{array}$ & & $\begin{array}{c}0.025 \\
(0.103) \\
\end{array}$ \\
\hline Mean in the control group & 52.056 & 79.092 & 48.657 & 70.207 & 2.919 & 2.813 & 2.942 & 2.909 \\
\hline Number of observations & 729 & 2,047 & 699 & 1,994 & 749 & 2,087 & 747 & 2,080 \\
\hline Prob > F(Conditional=Unconditional $)$ & & 0.616 & & 0.100 & & 0.186 & & 0.119 \\
\hline
\end{tabular}

Notes: Regressions are OLS models with robust standard errors clustered at the EA level. All regressions are weighted to make them representative of the target population in the study EAs. Baseline values of the following variables are included as controls in the regression analyses: age dummies, strata dummies, household asset index, highest grade attended, and an indicator for never had sex. Parameter estimates statistically different than zero at $99 \%(* * *), 95 \%(* *)$, and $90 \%(*)$ confidence. 
Table 7: Program impact on self-perceived standing in the household

\section{Dependent Variable}

$=1$ if household cares more about respondent's education than 12 months ago

$=1$ if household cares more about

\begin{tabular}{cc|cc}
\hline Round 2 & Round 3 & Round 2 & Round 3 \\
\hline
\end{tabular}
respondent's health than 12 months ago

\begin{tabular}{lll|ll}
\hline Dropouts & Schoolgirls Dropouts Schoolgirls & Dropouts Schoolgirls Dropouts Schoolgirls \\
\hline
\end{tabular}

Conditional Treatment

Unconditional Treatment

Mean in the control group

Number of observations

Prob > F(Conditional=Unconditional)

\begin{tabular}{cccc|cccc}
$(1)$ & $(2)$ & $(3)$ & $(4)$ & $(5)$ & $(6)$ & $(7)$ & $(8)$ \\
\hline $0.334 * * *$ & $0.075^{* *}$ & 0.017 & 0.032 & $0.067^{* *}$ & $0.158^{* * *}$ & 0.016 & 0.026 \\
$(0.038)$ & $(0.034)$ & $(0.027)$ & $(0.033)$ & $(0.034)$ & $(0.045)$ & $(0.030)$ & $(0.029)$ \\
& $0.165^{* * *}$ & & 0.034 & & $0.183^{* * *}$ & & $0.081^{*}$ \\
& $(0.036)$ & & $(0.036)$ & & $(0.043)$ & & $(0.043)$ \\
\hline 0.161 & 0.524 & 0.141 & 0.416 & 0.242 & 0.255 & 0.201 & 0.288 \\
733 & 2,077 & 728 & 2,076 & 732 & 2,075 & 728 & 2,072 \\
& 0.034 & & 0.961 & & 0.686 & & 0.262 \\
\hline
\end{tabular}

Notes: Regressions are OLS models with robust standard errors clustered at the EA level. All regressions are weighted to make them representative of the target population in the study EAs. Baseline values of the following variables are included as controls in the regression analyses: age dummies, strata dummies, household asset index, highest grade attended, and an indicator for never had sex. Parameter estimates statistically different than zero at $99 \%(* * *), 95 \%(* *)$, and $90 \%(*)$ confidence. 
Table 8: Program impact on nutrition and health

\begin{tabular}{|c|c|c|c|c|c|c|c|c|}
\hline & \multicolumn{4}{|c|}{$\begin{array}{l}\text { Number of Times Respondent Ate Protein } \\
\text { Rich Food in Past } 7 \text { Days (out of 21) }\end{array}$} & \multicolumn{4}{|c|}{$\begin{array}{c}=1 \text { if Respondent Usually Sleeps Under a Bed } \\
\text { Net }\end{array}$} \\
\hline & \multicolumn{2}{|c|}{ Round 2} & \multicolumn{2}{|c|}{ Round 3} & \multicolumn{2}{|c|}{ Round 2} & \multicolumn{2}{|c|}{ Round 3} \\
\hline & Dropouts & Schoolgirls & Dropouts & Schoolgirls & Dropouts & Schoolgirls & Dropouts & Schoolgirls \\
\hline & $(1)$ & $(2)$ & (3) & $(4)$ & (5) & $(6)$ & $(7)$ & $(8)$ \\
\hline Conditional Treatment & $\begin{array}{l}0.340^{*} \\
(0.189)\end{array}$ & $\begin{array}{r}0.489 * * \\
(0.202)\end{array}$ & $\begin{array}{c}0.120 \\
(0.188)\end{array}$ & $\begin{array}{c}0.530 * * * \\
(0.179)\end{array}$ & $\begin{array}{l}-0.022 \\
(0.040)\end{array}$ & $\begin{array}{l}0.078^{*} \\
(0.040)\end{array}$ & $\begin{array}{c}0.028 \\
(0.032)\end{array}$ & $\begin{array}{l}0.085^{*} \\
(0.044)\end{array}$ \\
\hline Unconditional Treatment & & $\begin{array}{c}0.434 * * \\
(0.184) \\
\end{array}$ & & $\begin{array}{l}0.282 * \\
(0.165) \\
\end{array}$ & & $\begin{array}{l}-0.015 \\
(0.066) \\
\end{array}$ & & $\begin{array}{c}0.009 \\
(0.055) \\
\end{array}$ \\
\hline Mean in the control group & 3.662 & 3.954 & 4.076 & 4.084 & 0.584 & 0.493 & 0.724 & 0.659 \\
\hline Number of observations & 750 & 2087 & 749 & 2086 & 746 & 2081 & 748 & 2084 \\
\hline Prob $>\mathrm{F}($ Conditional=Unconditional $)$ & & 0.827 & & 0.255 & & 0.204 & & 0.228 \\
\hline
\end{tabular}

Notes: Regressions are OLS models with robust standard errors clustered at the EA level. All regressions are weighted to make them representative of the target population in the study EAs. Baseline values of the following variables are included as controls in the regression analyses: age dummies, strata dummies, household asset index, highest grade attended, and an indicator for never had sex. Parameter estimates statistically different than zero at $99 \%(* * *), 95 \%(* *)$, and $90 \%(*)$ confidence. 
Appendix Table A: Additional Program Impacts on Baseline Dropouts in Round 3

\begin{tabular}{|c|c|c|c|c|c|c|}
\hline & $\begin{array}{c}\text { Number Terms } \\
\text { Enrolled (out } \\
\text { of 6) } \\
\end{array}$ & $\begin{array}{c}\text { English Test Score } \\
\text { (standardized) }\end{array}$ & $\begin{array}{c}\text { Math Test Score } \\
\text { (standardized) }\end{array}$ & $\begin{array}{c}\text { Cognitive Test } \\
\text { Score } \\
\text { (standardized) }\end{array}$ & $\begin{array}{c}\text { Ever } \\
\text { Pregnant } \\
\end{array}$ & $\begin{array}{c}\text { Ever } \\
\text { married }\end{array}$ \\
\hline & (1) & $(2)$ & (3) & (4) & $(5)$ & (6) \\
\hline Conditional Treatment & $\begin{array}{c}2.348 * * * \\
(0.163) \\
\end{array}$ & $\begin{array}{l}0.131^{*} \\
(0.070) \\
\end{array}$ & $\begin{array}{c}0.164 * * \\
(0.066) \\
\end{array}$ & $\begin{array}{c}0.142 * * \\
(0.071) \\
\end{array}$ & $\begin{array}{c}-0.082 * * * \\
(0.027) \\
\end{array}$ & $\begin{array}{c}-0.126^{* * *} * \\
(0.036) \\
\end{array}$ \\
\hline Mean in the control group & 1.021 & 0.000 & 0.000 & 0.000 & 0.780 & 0.551 \\
\hline Number of observations & 749 & 729 & 729 & 729 & 749 & 749 \\
\hline
\end{tabular}

